\title{
PENGARUH PENAMBAHAN MALEAT ANHIDRIDA-GRAFTED- POLIPROPILENA TERHADAP SIFAT KEKUATAN BENTUR DAN PENYERAPAN AIR KOMPOSIT HIBRID PLASTIK BEKAS KEMASAN GELAS BERPENGISI SERBUK SERAT AMPAS TEBU DAN SERBUK SERAT KACA
}

\author{
Castiqliana, Silvia, Halimatuddahliana \\ Departemen Teknik Kimia, Fakultas Teknik, Universitas Sumatera Utara, \\ Jalan Almamater Kampus USU Medan, 20155, Indonesia \\ Email : castiqliana@yahoo.com
}

\begin{abstract}
Abstrak
Penelitian tentang komposit hibrid plastik bekas kemasan gelas jenis polipropilena/serbuk serat ampas tebu termodifikasi/serbuk serat kaca tipe-E dengan penambahan penyerasi maleat anhidrida-g-polipropilena telah dilakukan dan sifat kekuatan bentur dan penyerapan air dianalisa. Komposisi serbuk serat kaca dan maleat anhidrida-g-polipropilena dibuat seragam yaitu $10 \%(\mathrm{~b} / \mathrm{b})$ dan $2 \%(\mathrm{~b} / \mathrm{b})$, serta komposisi serbuk serat ampas tebu termodifikasi divariasikan dari $10-40 \%(\mathrm{~b} / \mathrm{b})$. Modifikasi permukaan serbuk serat ampas tebu dengan natrium hidroksida $1 \%$ juga dilakukan. Proses pembuatan komposit hibrid dilakukan di dalam ekstruder. Hasil uji bentur menunjukkan bahwa pada penambahan serbuk serat ampas tebu termodifikasi $30 \%(b / b)$ diperoleh kekuatan bentur maksimum, yaitu $46,6 \mathrm{~J} / \mathrm{cm}^{2}$. Hasil uji bentur yang diperoleh didukung oleh analisa Scanning Electron Microscopy. Hasil analisa penyerapan air menunjukkan peningkatan serapan air dengan bertambahnya jumlah pengisi dan penyerapan air pada komposit yang menggunakan maleat anhidrida-gpolipropilena lebih rendah dari pada komposit yang tidak menggunakan maleat anhidrida-g-polipropilena pada komposisi pengisi yang sama.
\end{abstract}

Kata kunci : maleat anhidrida-g-polipropilena, penyerapan air, serat ampas tebu termodifikasi, serat kaca, uji bentur

\begin{abstract}
A study on wasted polypropylene/modified bagasse fiber flour/E-type glass fiber flour with maleic anhydrideg-polypropylene addition hybrid composite was performed and its impact properties and water absorption ability was analyzed. Glass fiber flour and maleic anhydride-g-polypropylene compositions were made constant at $10 \mathrm{wt} . \%$ and $2 \mathrm{wt} . \%$ respectively, and modified bagasse fiber flour composition was varied from $10-40$ wt. \%. Surface modification on bagasse flour with $1 \%$ sodium hydroxide was also conducted. The composites were prepared in an extruder. The result showed that the maximum impact strength of 46,6 J/cm ${ }^{2}$ was obtained in addition of modified bagasse fiber flour of $30 \mathrm{wt} \%$. Impact strength result was also supported by Scanning Electron Microscopy analysis. Water absorption test showed that the increase of modified bagasse fiber flour content resulted to the increase of water absorbance and composites with maleic anhydride-g-polypropylene addition had lower ability to absorb water when compared to composite without maleic anhydride-g-polypropylene addition in the same fillers content.
\end{abstract}

Keywords : maleic anhydride-g-polipropilene, water absorption, modified bagasse fiber, glass fiber, impact strength

\section{Pendahuluan}

Dalam beberapa dekade terakhir, para peneliti telah melakukan beragam penelitian untuk menggantikan komposit polimer dengan komposit hibrid karena masalah lingkungan dan sifat material yang terbatas pada komposit konvensional. Komposit hibrid adalah suatu sistem yang terdiri dari 2 jenis pengisi dalam 1 matriks ataupun 1 jenis pengisi dalam 2 jenis matriks yang berbeda [2]. Sifat bahan yang dihasilkan komposit hibrid pada umumnya merupakan gabungan dari sifat masingmasing bahan penyusun. Penambahan lebih dari satu jenis pengisi/matriks bertujuan untuk menutupi kekurangan dari pengisi/matriks lainnya dan ini akan menghasilkan keseimbangan antara biaya dan sifat material.

Pengelolaan limbah plastik merupakan salah satu masalah yang dihadapi negara berkembang seperti Indonesia. Indonesia sebagai salah satu negara dengan populasi tertinggi menghasilkan 5,4 juta ton plastik per tahun (14\% dari produksi sampah di Indonesia). Memanfaatkan plastik bekas kemasan gelas (PBKG) akan menjadi solusi yang baik untuk meminimalisir limbah plastik yang bersifat non-biodegradable. Akan tetapi, PBKG yang didaur ulang akan menghasilkan material dengan sifat mekanik yang rendah [16] sehingga perlu ditambahkan pengisi untuk meningkatkan sifat tersebut [7, 11].

Dampak buruk terhadap lingkungan telah menjadi alasan yang mendukung untuk mengganti pembuatan komposit dari serat sintetik dengan serat alami. Akan tetapi, komposit berpengisi serat alami akan menghasilkan sifat mekanik dan ketahanan terhadap air yang. rendah ketika dibandingkan dengan komposit dari serat sintetik (seperti serat 
kaca). Oleh karena itu, untuk menutupi kelemahan ini, serat kaca dan serat alami dikombinasikan dalam suatu matriks untuk menghasilkan komposit hibrid yang akan memiliki sifat terbaik dari masingmasing pengisi, sehingga sebuah komposit dengan sifat mekanik yang superior, ekonomis dan ramah lingkungan dapat terbentuk. Serat ampas tebu dipilih sebagai serat alami dalam penelitian ini karena ketersediaannya yang melimpah (54 juta ton per tahun di seluruh dunia) [3]. Selain itu, ampas tebu juga memiliki jumlah selulosa yang tinggi $(55,3 \%)$ yang dapat membentuk komposit yang kaku dan kuat [5].

Mengkombinasikan material yang bersifat polar seperti serat ampas tebu dan PBKG akan menghasilkan inkompatibilitas antara matriks dan pengisi. Oleh karena itu, modifikasi kimia dapat dilakukan pada serat ampas tebu untuk mengurangi kepolarannya [17]. Serat yang telah termodifikasi ini juga dapat mengurangi kemampuan komposit untuk menyerap air [18]. Penyerasi seperti maleat anhidrida-g-polipropilena (MAPP) juga dapat digunakan untuk meningkatkan kompatibilitas antara matriks dan pengisi.

\section{Teori}

Komposit adalah jenis material yang dibuat dengan mengkombinasikan dua atau lebih bahan yang berbeda. Bahan-bahan ini digabungkan untuk menghasilkan material baru yang memiliki sifat yang tidak dimiliki oleh bahan-bahan penyusunnya. Jadi, secara teknis komposit dapat didefinisikan sebagai material multifasa yang diperoleh dari kombinasi bahan-bahan yang berbeda namun tetap memiliki karakter dan sifat dari bahan-bahan penyusunnya, tanpa mengalami reaksi kimia. Komponen-komponen bahan ini tidak saling melarut ataupun bergabung sepenuhnya. Mereka memiliki suatu interfasa antara satu dengan lainnya yang berfungsi untuk menghasilkan suatu karakter yang sinergis dimana karakter ini tidak dapat diperoleh dari komponen bahan penyusunnya secara tunggal [8].

Komposit hibrid merupakan salah satu jenis komposit yang saat ini banyak dikembangkan. Kata "hybrid" berasal dari Yunani-Latin dan banyak ditemui pada beragam bidang ilmu. Dalam bidang polimer komposit, komposit hibrid merupakan suatu pengisi yang berada dalam matriks berbeda (blend) atau juga dapat berupa dua atau lebih pengisi yang berada dalam suatu matriks [9]. Komposit hibrid banyak dikembangkan dengan mengkombinasikan dua jenis serat berbeda dalam suatu matriks dimana kedua jenis pengisi dapat saling menutupi kekurangan satu sama lainnya, sehingga keseimbangan antara biaya dan sifat bahan dapat diperoleh dengan desain bahan yang baik [13]. Salah satu contoh adalah penambahan serat kevlar 49 yang lebih bersifat liat ke dalam komposit diperkuat serat karbon yang bersifat rapuh. Penambahan serat kevlar 49 tersebut telah dibuktikan dapat meningkatkan kekuatan impak komposit tersebut. Selain itu, komposit hibrid juga digunakan untuk tujuan mengurangi biaya. Misalnya suatu jumlah serat yang berkualitas lebih rendah dan murah dapat ditambahkan ke dalam komposit diperkuat serat karbon atau boron tanpa menyebabkan penurunan sifat mekanik yang signifikan [12].

Ketidakcocokkan akibat perbedaan sifat polaritas antara pengisi dan matriks dapat menyebabkan suatu masalah dalam pemrosesan komposit. Modifikasi kimia pada pengisi dapat menjadi solusi untuk mengatasi ketidakcocokkan tersebut. Modifikasi kimia pada pengisi alami yang mengandung selulosa didefinisikan sebagai reaksi antara beberapa bagian reaktif dari polimer dinding sel lignoselulosa dengan pelarut kimia tunggal, baik dengan katalis ataupun tanpa katalis untuk membentuk ikatan kovalen antara keduanya. Modifikasi kimia pada pengisi ini bertujuan untuk meningkatkan sifat-sifat dari pengisi tersebut. Secara umum, modifikasi kimia dapat mengurangi jumlah gugus $\mathrm{OH}$ pada pengisi, mengurangi lignin, pektin, wax dan minyak pada permukaan dinding sel pengisi [14].

Penguatan alkali adalah salah satu teknik penguatan kimia yang banyak digunakan pada serat alam apabila dipakai sebagai penguat pada matriks termoplastik dan termoset. Modifikasi penguatan alkali akan merusak ikatan hidrogen dan cara demikian akan membuat permukaan serat menjadi lebih kasar. Adanya penguatan alkali pada serat akan menghilangkan sejumlah lignin, lilin dan minyak pada permukaan serat dinding, sehingga terjadi depolimerisasi pada selulosa dan membuat serat lebih pendek.

Oleh karenanya proses alkalisasi serat selulosa langsung pada derajat polimerisasi dan menghilangkan lignin dan senyawa hemiselulosa. Dalam penguatan alkali, serat dimasukkan kedalam larutan $\mathrm{NaOH}$ dengan waktu yang tertentu. Dalam komposit polimer, teknik penguatan alkali pada serat selulosa merupakan modifikasi kimia yang telah dilakukan untuk meningkatkan adhesi antara permukaan serat selulosa dan matriks polimer karena menghasilkan ikatan yang baik [10].

Selain itu, dalam suatu campuran multifasa, banyak perhatian ditujukan pada daerah permukaan antar fasa dimana terjadi interaksi antar fasa dan tenaga pendorong untuk pemisahan fasa. Hal ini umumnya dinyatakan sebagai tegangan antar muka antar fasa yang merupakan perilaku mekanik dari sistem multifasa yang juga tergantung pada karakteristik antarmuka dan kemampuannya untuk mengatur tegangan dari satu fasa ke fasa lain. Secara normal, batas fasa adalah titik lemah dalam materi. Dengan demikian, adhesi antara fase memiliki pengaruh penting tentang bagaimana campuran akan merespon terhadap stres [6]. 
Proses modifikasi sifat antarmuka dari polimer campuran untuk pembuatan campuran polimer disebut kompatibilisasi. Tujuan utama kompatibilisasi adalah untuk menstabilkan dispersi yang baik terhadap aglomerasi (penumpukan) selama berlangsungnya proses dan mencapai suatu morfologi yang seimbang yang akan memberikan tegangan halus yang ditransfer dari satu fasa ke fasa yang lain dan digunakan untuk menahan gangguan (kerusakan) tegangan yang lebih besar [6].

\section{Metodologi Penelitian \\ Bahan}

Plastik bekas kemasan gelas (PBKG) diperoleh dari limbah konsumsi air mineral kemasan gelas. PBKG dipotong menjadi ukuran yang kecil $( \pm 5 \mathrm{~mm} \times 5 \mathrm{~mm})$. Serat ampas tebu diperoleh dari limbah penjualan air tebu. Serat ampas tebu diekstraksi dari bagian dalam pulp ampas tebu dan dikeringkan di bawah sinar matahari selama 3 hari, serta digiling dengan ball mill menjadi partikel ukuran 100 mesh. Komposisi kimia serat ampas tebu dapat dilihat pada Tabel 1.

Tabel 1 Komposisi Kimia Serat Ampas Tebu [2]

\begin{tabular}{|c|c|}
\hline Komponen & Kadar \\
\hline Selulosa (\%) & 55,3 \\
Hemiselulosa (\%) & 18,8 \\
Lignin (\%) & 21,0 \\
Zat Ekstraktif (\%) & 2,9 \\
Abu (\%) & 1,9 \\
\hline
\end{tabular}

Serat kaca tipe-E diperoleh dari PT. Justus Kimiaraya (Medan, Indonesia). Serat kaca digiling dengan ball mill menjadi partikel ukuran 100 mesh. Xilena komersial diperoleh dari CV. Rudang Jaya (Medan, Indonesia). Polipropilena isotaktik (melt flow index $14 \mathrm{~g} / 10$ menit) diperoleh dari Titan PP Polymers (TitanPro 6331 grade) (Johor, Malaysia). Maleat andhirida, aseton dan benzoil peroksida diperoleh dari Merck Indonesia.

\section{Modifikasi Alkali}

Serbuk serat ampas tebu direndam dalam natrium hidroksida $(\mathrm{NaOH}) 1 \%$ pada suhu ruangan selama 2 jam dengan rasio cairan 2:1. Serbuk serat ampas tebu dicuci beberapa kali dengan aquades untuk menghilangkan $\mathrm{NaOH}$ yang masih melekat pada serat. Serat kemudian dinetralisir dengan 0,1 $\mathrm{M}$ asam asetat dan kemudian dicuci lagi dengan air. Serbuk serat ampas tebu termodifikasi (SSAT) yang diperoleh kemudian dikeringkan di dalam oven 70 ${ }^{\circ} \mathrm{C}$ selama 72 jam.

\section{Sintesa Penyerasi}

Maleat anhidrida-g-polipropilena (MAPP) disintesa dari reaksi refluks $1 \mathrm{~g}$ maleat anhidrida, 10 g polipropilena dan $90 \mathrm{ml}$ xilena pada suhu $135{ }^{\circ} \mathrm{C}$ selama 20 menit. $0,1 \mathrm{~g}$ benzoil peroksida yang telah dilarutkan dalam $10 \mathrm{ml}$ xilena ditambahkan ke dalam reaksi dan direaksikan selama 10 menit. Hasil reaksi dicuci dengan aseton untuk mengendapkan MAPP. MAPP disaring dan dicuci dengan aquades hingga $\mathrm{pH}$-nya netral. MAPP dikeringkan di dalam blower selama 24 jam dan digiling dengan ball mill menjadi partikel ukuran 100 mesh.

\section{Pembuatan Komposit}

Formulasi komposisi komponen komposit disajikan pada Tabel 2. Komposit dibuat dengan 2 tahap proses. Pada tahap pertama, PBKG, SSAT, SSK dan MAPP dicampur secara mekanik sesuai dengan formulasi dan kemudian campuran dimasukkan ke dalam ekstruder. Profil temperatur dijaga pada $180{ }^{\circ} \mathrm{C}$. Pada tahap kedua, benang ekstrudat digranulasi secara manual dan kemudian didinginkan dalam water bath. Biji ekstrudat yang diperoleh kemudian dikeringkan pada suhu $105{ }^{\circ} \mathrm{C}$ selama 24 jam sebelum dicetak pada mesin hot press pada suhu $180^{\circ} \mathrm{C}$.

Tabel 2. Formulasi Komposisi Komponen Komposit

\begin{tabular}{|c|c|c|c|c|}
\hline $\begin{array}{c}\text { Kode } \\
\text { Sampel }\end{array}$ & $\begin{array}{c}\text { PBKG } \\
\%(\mathrm{~b} / \mathrm{b})\end{array}$ & $\begin{array}{c}\text { SSAT } \\
\%(\mathrm{~b} / \mathrm{b})\end{array}$ & $\begin{array}{c}\text { SSK } \% \\
(\mathrm{~b} / \mathrm{b})\end{array}$ & $\begin{array}{c}\text { MAPP } \\
\%(\mathrm{~b} / \mathrm{b})\end{array}$ \\
\hline 1. & 80 & 10 & 10 & 0 \\
2. & 78 & 10 & 10 & 2 \\
3. & 70 & 20 & 10 & 0 \\
4. & 68 & 20 & 10 & 2 \\
5. & 60 & 30 & 10 & 0 \\
6. & 58 & 30 & 10 & 2 \\
7. & 50 & 40 & 10 & 0 \\
8. & 48 & 40 & 10 & 2 \\
\hline
\end{tabular}

\section{Pengukuran Uji Bentur}

Uji kekuatan bentur dilakukan sesuai dengan standar ASTM D 4812-11. Uji bentur Izod dilakukan pada spesimen yang memiliki ukuran dimensi $60 \times 10 \times 3 \mathrm{~mm}$.

\section{Analisa Penyerapan Air}

Analisa penyerapan air dilakukan sesuai dengan standar ASTM D 570. Spesimen berukuran $25 \mathrm{~mm}$ x $25 \mathrm{~mm}$ pada suhu $50 \pm 5{ }^{\circ} \mathrm{C}$ selama 24 jam. Massa masing-masing spesimen ditimbang dan setelah itu, dilakukan perendaman spesimen komposit dalam air. Massa spesimen ditimbang setiap 24 jam hingga diperoleh massa yang konstan. Sampel kemudian ditimbang dan dihitung dengan persamaan (1).

$\mathrm{W}_{\mathrm{g}}=\frac{\mathrm{W}_{\mathrm{e}}-\mathrm{W}_{\mathrm{o}}}{\mathrm{W}_{\mathrm{o}}} \times 100 \%$

Dimana :

$\mathrm{W}_{\mathrm{g}}=$ Persentase pertambahan massa komposit (\%)

$\mathrm{W}_{\mathrm{e}}=$ Massa komposit setelah perendaman $(\mathrm{g})$

$\mathrm{W}_{\mathrm{o}}=$ Massa komposit sebelum perendaman $(\mathrm{g})$ 
Analisa Scanning Electron Analysis (SEM)

Analisa SEM dilakukan dengan menggunakan HITACHI TM13000. Tegangan akselerasi sebesar 5 $\mathrm{kV}$ digunakan untuk mendapatkan gambar SEM.

\section{Hasil}

\section{Kekuatan Bentur}

Gambar 1 menunjukkan pengaruh komposisi pengisi serbuk serat ampas tebu termodifikasi (SSAT) terhadap kekuatan bentur (impact strength) komposit hibrid plastik bekas kemasan gelas (PBKG) jenis polipropilena berpengisi serbuk serat ampas tebu termodifikasi (SSAT) dan serbuk serat kaca (SSK) dengan penambahan bahan penyerasi maleat anhidrida-g-polipropilena (MAPP).

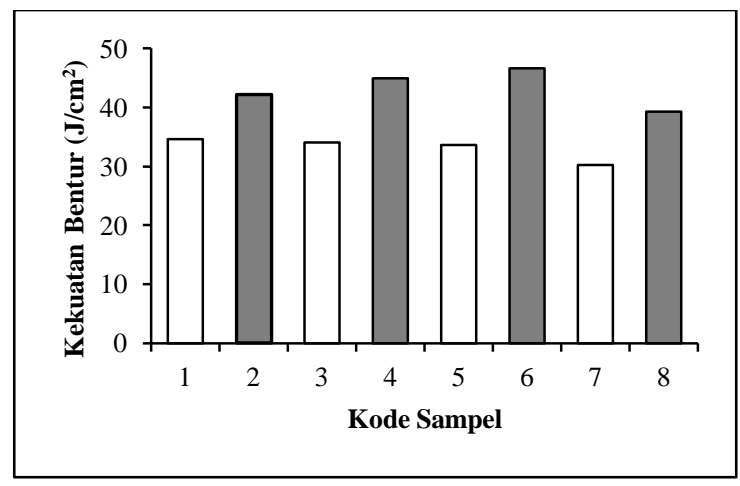

Gambar 1. Pengaruh Komposisi Serbuk Serat Ampas Tebu Termodifikasi Terhadap Kekuatan Bentur (Impact Strength) Komposit Hibrid Plastik Bekas Kemasan Gelas (PBKG) Jenis Polipropilena

Kekuatan bentur komposit adalah suatu pengukuran atas kemampuan material untuk menahan patahan akibat tekanan yang disebabkan oleh kecepatan tinggi dimana nilai yang dihasilkan menunjukkan ketangguhan material [19] yang sangat dipengaruhi oleh kekuatan ikatan interfasa, sifat matriks dan pengisi [2]. Pada komposit hibrid yang tidak menggunakan penyerasi MAPP, terjadi penurunan sifat kekuatan bentur seiring dengan bertambahnya komposisi pengisi alami. Hal ini disebabkan oleh ikatan interfasa yang buruk antara matriks dan pengisi yang mengakibatkan mudahnya terjadi keretakan pada daerah interfasa [1]. Bertambahnya jumlah pengisi mengakibatkan ikatan antara pengisi dan matriks semakin sulit di daerah interfasa karena bertambahnya kontak antar pengisi. Hasil yang sama juga diperoleh oleh Chern Chiet Eng, dkk (2014) [4] bahwa penambahan jumlah pengisi dapat menurunkan kekuatan tarik komposit tanpa menggunakan penyerasi.

Peningkatan kekuatan bentur disebabkan karena adanya peran pengisi dalam meningkatkan ketahanan bentur dari komposit, dalam hal ini pengisi berinteraksi dengan titik pembentukan patahan (crack formation) dan media pemindahan tegangan (stress transferring medium) [19]. Dengan demikian, dapat disimpulkan bahwa meningkatnya kandungan bahan pengisi maka bahan komposit akan dapat menyerap energi benturan yang lebih tinggi. Penurunan kekuatan bentur terjadi pada komposit hibrid dengan rasio 48/40/10/2. Hal ini disebabkan oleh karena peningkatan jumlah pengisi SSAT yang kemudian meningkatkan kontak antar sesama pengisi sehingga menurunkan pemindahan tegangan efektif antara matriks dan pengisi [2]. Penggunaan MAPP memberikan efek nyata untuk meningkatkan hubungan interfasa yang baik antara matriks dan pengisi yang dapat meningkatkan sifat kekuatan bentur komposit.

Karakterisasi morfologi SEM (Scanning Microscopy Analysis) patahan komposit dengan sifat kekuatan bentur terbaik (rasio 58/30/10/2) dengan penggunaan MAPP dapat dilihat pada Gambar 2 berikut.

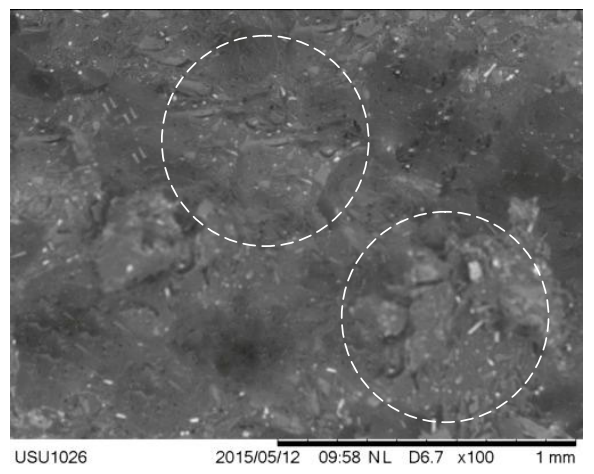

(a)

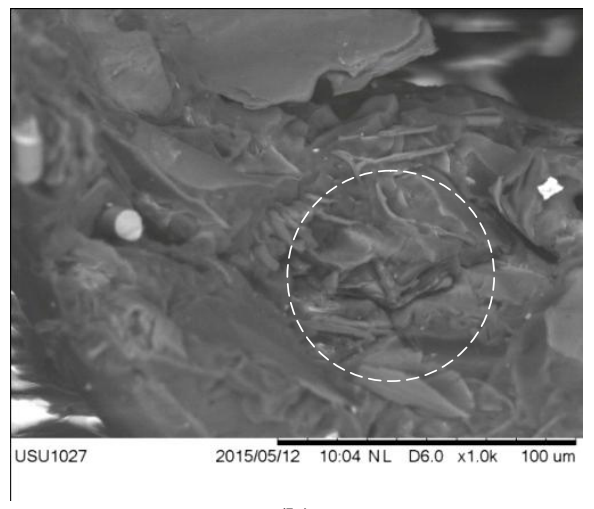

(b)

Gambar 2. Analisis SEM (Scanning Electron Microscopy) (a) Morfologi Patahan Komposit Hibrid 58/30/10/2 dengan Perbesaran 100x (b) Morfologi Patahan Komposit Hibrid 58/30/10/2 dengan Perbesaran 1000x

Dari Gambar 2 (a) dapat dilihat morfologi patahan uji bentur komposit hibrid yang memiliki distribusi pengisi yang baik dan padat. Pengisi yang masih melekat dengan baik pada matriks setelah diberikan benturan menunjukkan bahwa komposit memiliki interfasa yang baik antara matriks dan pengisi. Hal ini juga ditunjukkan oleh Gambar 2 (b) 
yang telah mengalami perbesaran 1000x bahwa kedua pengisi terdispersi dan menyatu dengan matriks membentuk suatu kesatuan utuh.

Karakterisasi morfologi SEM (Scanning Microscopy Analysis) patahan komposit akibat benturan (rasio 60/30/10/0) tanpa penggunaan MAPP dapat dilihat pada Gambar 3 berikut.

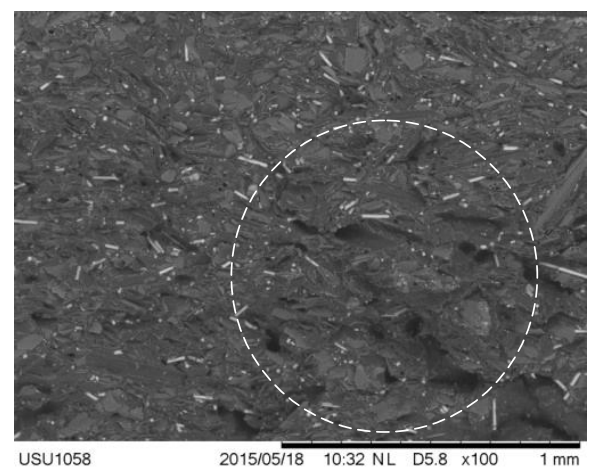

(a)

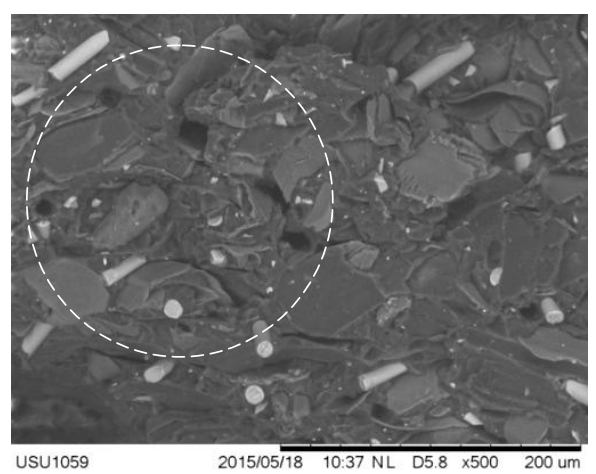

(b)

Gambar 3. Analisis SEM (Scanning Electron Microscopy) (a) Morfologi Patahan Komposit Hibrid 60/30/10/0 dengan Perbesaran 100x (b) Morfologi Patahan Komposit Hibrid 60/30/10/0 dengan Perbesaran 500x

Gambar 3 (a) dan (b) yang menunjukkan adanya area kosong yang terbentuk akibat terlepasnya pengisi dari matriks. Hal menunjukkan bahwa komposit memiliki interfasa yang kurang baik antara matriks dan pengisi akibat tidak adanya penggunaan penyerasi MAPP.

\section{Penyerapan Air}

Gambar 4 menunjukkan pengaruh komposisi pengisi serbuk serat ampas tebu termodifikasi terhadap sifat penyerapan air (water absorption) komposit hibrid plastik bekas kemasan gelas (PBKG) jenis polipropilena berpengisi serbuk serat ampas tebu termodifikasi (SSAT) dan serbuk serat kaca (SSK) dengan penambahan bahan penyerasi maleat anhidrida-g-polipropilena (MAPP).

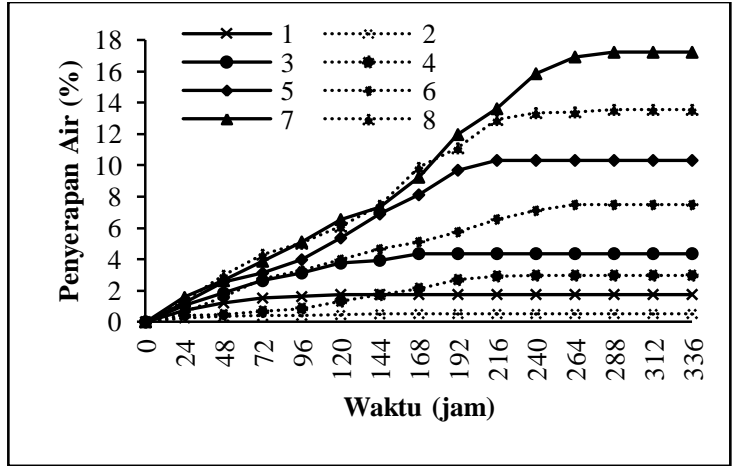

Gambar 4. Pengaruh Komposisi Serbuk Serat Ampas Tebu Termodifikasi Terhadap Sifat Penyerapan Air (Water Absorption) Komposit Hibrid Plastik Bekas Kemasan Gelas (PBKG) Jenis Polipropilena

Komposit dengan komposisi pengisi alami terbanyak memiliki nilai penyerapan air tertinggi baik pada maupun tanpa penggunaan MAPP. Penyerapan air pada komposit hibrid terbesar terjadi pada 240 jam pertama. Hal ini disebabkan karena pada masa awal perendaman, kemampuan pengisi untuk menyerap air masih sangat tinggi dan menyebabkan lebih banyak air dapat masuk ke dalam komposit, sehingga terjadi peningkatan nilai penyerapan air yang signifikan pada masa tersebut. Setelah itu, penyerapan air pada bahan komposit tidak terlalu signifikan lagi. Hal ini disebabkan karena kemampuan komposit dalam menyerap air telah menurun hingga pada akhirnya mencapai titik jenuh penyerapan air (berhenti menyerap air).

Peningkatan penyerapan air pada komposit tanpa penggunaan MAPP lebih signifikan daripada penggunaan MAPP pada komposisi pengisi yang sama. Hal ini disebabkan karena peranan MAPP yang menciptakan interaksi interfasa antara matriks dan pengisi sehingga mengurangi akumulasi air di dalam daerah interfasa [15]. Hasil yang sama juga diperoleh oleh Sanjay dan Smita (2009) [15] bahwa penambahan jumlah pengisi dapat meningkatkan sifat penyerapan air komposit. Ia juga melaporkan bahwa komposit yang tidak menggunakan MAPP memiliki nilai penyerapan air yang lebih tinggi daripada komposit yang menggunakan MAPP pada jumlah pengisi yang sama.

\section{Kesimpulan}

Adapun kesimpulan yang diperoleh dari penelitian ini adalah :

1. Hasil kekuatan bentur maksimum komposit yaitu $46,6 \mathrm{~J} / \mathrm{cm}^{2}$ diperoleh pada penambahan SSAT sebesar 30\%(b/b).

2. Berdasarkan uji penyerapan air komposit diketahui bahwa penambahan jumlah pengisi SSAT dapat meningkatan tingkat penyerapan air dan penyerapan air pada komposit yang menggunakan MAPP lebih rendah daripada komposit yang tidak menggunakan MAPP pada komposisi pengisi yang sama. 
3. MAPP memberikan pengaruh besar dalam meningkatkan ikatan interfasa komposit yang dapat meningkatkan sifat kekuatan bentur komposit dan menurunkan daya serap air komposit.

\section{Daftar Pustaka}

[1] A. Arbelaiz, B. Fernandez, J. A. Ramos, A. Retegi, R. Liano - Ponte, dan I. Mondragon, Mechanical properties of short flax fibre bundle/polypropylene composites : Influence of matrix/fibre modification, fibre content, water uptake and recycling, Composites Science and Technology, 65 : 1582 - 1592, 2005.

[2] Alireza Ashori, Amir Nourbakhsh, Ali Kazemi Tabrizi, Thermoplastic Hybrid Composites using Bagasse, Corn Stalk and E glass Fibers : Fabrication and Characterization, Polymer - Plastics Technology and Engineering, $53: 1$ - 8, 2014.

[3] B. Ramaraj, Mechanical and Thermal Properties of Polypropylene/ Sugarcane Bagasse Composites, Wiley Inter Science, 103 : 3827 - 3832, 2007.

[4] Chern Chiet Eng, Nor Azowa Ibrahim, Norhazlin Zainuddin, Hidayah Ariffin dan Wan Md. Zin Wan Yunus, Impact Strength and Flexural Properties Enhancement of Methacrylate Silane Treated Oil Palm Mesocarp Fiber Reinforced Biodegradable Hybrid Composites, The Scientific World Journal, 2014.

[5] D. Nabi Saheb dan J. P. Jog, Natural Fiber Polymer Composites : A Review, Advances in Polymer Technology, 18(4) : 351 - 363, 1999.

[6] Erna Frida, Penggunaan Anhidrida Maleat Grafted - Polipropilena (AM - g - PP) dan Anhidrida Maleat - Grafted - Karet Alam (AM - g - KA) pada Termoplastik Elastomer (TPE) Berbasis Polipropilena, Kompon Karet Alam SIR - 20 dan Serbuk Ban Bekas, Disertasi, Universitas Sumatera Utara, 2011.

[7] Halimatuddahliana, Buku Ajar Pengenalan Teknologi Polimer, Penerbit Universitas Sumatera Utara, Medan, 2008, p. 32 - 42, 47 48.

[8] J. P. Agrawal, Composite Materials, Penerbit Defence Scientific Information \& Documentation Center, Delhi, 1990, p. 9 - 10, $17-18,25-27$.

[9] Klaus Friedrich, Stoyko Fakirov dan Zhong Zhang, Polymer Composites from Nano - to Macro - Scale, Penerbit Springer, New York 2005 , p. 314.

[10] Lely Risnawaty Daulay, Adhesi Penguat Serbuk Pulp Tandan Kosong Sawit Teresterifikasi dengan Matriks Komposit Polietilena, Disertasi, Universitas Sumatera Utara, 2009.
[11] M. A. Al - Maadeed, Yasser M. Shabana, P. Noorunnisa Khanam, Processing, characterization and modeling of recycled polypropylene/glass fibre/wood flour composites, Materials and Design 58 :374 380, 2014.

[12] Maulida, Kajian Terhadap Hibrid Komposit Berasaskan Gentian Lignoselulosik, Tesis, Universiti Sains Malaysia, 2001.

[13] M. Jawaid dan H. P. S. Abdul Khalil, Cellulosic/synthetic fibre reinforced polymer hybrid composites : A review, Carbohydrate Polymers, $86: 1$ - 18, 2011.

[14] Nahlom Dahlan Marpaung, Pemanfaatan Selulosa dari Tandan Kosong Kelapa Sawit Sebagai Bahan Pengisi Komposit Polietilena Densitas Rendah (LDPE), Tesis, Universitas Sumatera Utara, 2011.

[15] Sanjay K. Nayak dan Smita Mohanty, Sisal Glass Fiber Reinforced PP Hybrid Composites : Effect of MAPP on the Dynamic Mechanical and Thermal Properties, Journal of Reinforced Plastics and Composites, 2009.

[16] Shigeru Yao, Aya Tominaga, Youhei Fujikawa, Hiroshi Sekiguchi dan Eiichi Takatori, Inner Structure and Mechanical Properties of Recycled Polypropylene, Nihon Reoroji Gakkaishi, 41(3) : 173 - 178 : 2013.

[17] S. M. Luz, A. R. Goncalves, A. P. Del'Arco Jr, Mechanical behavior and microstructural analysis of sugarcane bagasse fibers reinforced polypropylene composites, Composites Part A : applied science and manufacturing : 1455 - 1461, 2007.

[18] Sonia M. B. Nachtigall, Graziela S. Cerveira, Simone M. L. Rosa, New polymeric coupling agent for polypropylene/wood - flour composites, Polymer Testing, 26 : 619 - 628, 2007.

[19] Suhara Panthapulakkal dan Mohini Sain, Injection - Molded Short Hemp Fiber/Glass Fiber - Reinforced Polypropylene Hybrid Composites - Mechanical, Water Absorption and Thermal Properties, Journal of Applied Polymer Science, 103 : 2432 - 2441, 2007. 